which ended in the hydra taking the entire insides out of the amœba. Here was indeed 'a struggle for existence' with a vengeance!

For myself, I do not propose to be deterred by doubtful principles of physics, from the most obvious inference that the animals, including the micro-organisms, have a true psychic existence; and that this psychic existence is a force, and an important force, for the preservation or destruction of the species. Only the settlement by biology of the disputed question as to the limits of heredity can decide how much psychic forces count for in the modification and direction of the physical evolution of species. Without emotion and what we call instinct to act as vera causa in the evolution of their organisms, the world of animal forms would be a system of pale shadows, moved by toy-like mechanism, compared with the exceedingly interesting and dreadfully earnest thing which it now is.

It is here, of course, however, that comparative psychology and biology came so close to each other; indeed, seem to run together. And comparative psychology-as the very term signifies-cannot be cultivated without knowledge of human psychology. Here, therefore, I am brought around again to the remark with which I started. Such a conference as this is significant of the unity of interest that maintains itself among the sciences; and it is promising of a more warm sympathy and a more helpful intercourse between them.

YALE UNIVERSITY.

Grorge Trumbull Ladd.

\title{
CONSCIOUSNESS AND EVOLUTION. ${ }^{1}$
}

The addresses to which we have already listened by Professors James and Cope have raised so many interesting questions, and the various aspects of the general problem have been so clearly formulated, that I shall confine myself to a few remarks upon the positions which these speakers have taken.

Professor Cope's position on the place of consciousness in evolution seems in the main the true one, as far as the question of fact is concerned. I agree with him that no adequate theory of the development of organic nature can be formulated without taking conscious states into account. The fact of adaptation requires on the part of the individual organism something equivalent to what we call consciousness

Discussion (revised) before the Amer. Psychol. Assoc., at Philadelphia, Dec. 28, 1895 . 
in ourselves. But I do not think that the need of recognizing consciousness in connection with organic functions leads at all necessarily to the view that conciousness is a causa vera whose modes of action do not have physiological parallel processes in the brain and nerves. The alternatives are not really two only, automatism-a theory of mechanical causation of all movement, with the inference that consciousness is a by-product of no importance, and this vera causa view which makes consciousness a new force injected into the activities of the brain. There is another way of looking at the question to which I return below.

With Professor Cope's view that the recognition of consciousness as a factor in evolution requires a Neo-Lamarckian theory of heredity I am not at all in accord. I have recently discussed the question apropos of Professor Cope's views in Science (Aug. 23, 1895). Instead of finding with Professor Cope that the emphasis of conscious function in evolution makes it necessary to recognize the Lamarckian factor, I think the facts point just the other way. As soon as there is much development of mind, the gregarious or social life begins; and in it we have a new way of transmitting the acquisitions of one generation to another, which tends to supersede the action-if it existsof natural heredity in such transmission. This transmission by 'Social Heredity' (as we may call the individual's process of learning from society by imitation, instruction, etc.,) is so universal a fact with vertebrates that we may, it seems to me, say at once that the arguments for Neo-Lamarckism drawn by Mr. Spencer and others from the phenomena of human progress, at least, are completely neutralized by them. And there are facts which should show that the same state of things descend below man.

It is very probable, as far as the early life of the child may be taken as indicating the factors of evolution, that the main function of consciousness is to enable him to learn things which natural heredity fails to transmit; and with the child the fact that consciousness is the essential means of all his learning is correlated with the other fact that the child is the very creature for which natural heredity gives few independent functions. It is in this field only that I venture to speak with assurance; but the recognition of this influence has been reached by Weismann, Morgan and others on the purely biological side.

The instinctive equipment of the lower animals is replaced by the plasticity necessary for learning by consciousness. So it seems to me that the evidence points to some inverse ratio between the importance of consciousness as factor in development and the need of the inheri- 
tance of acquired characters as factor in development. This presumptive argument may be supplemented, I think, with positive refutations of the considerations which Professor Cope, Romanes and others present for the view that the transmission of functions secured by consciousness requires the Lamarckian factor. ${ }^{2}$

The examination of the biological evidence just cited by $\mathrm{Mr}$. Cope in support of Neo-Lamarckism I am not competent to make; but there is present another distinguished biologist, Prof. Minot, from whom I hope we may hear.

There is one omission in Professor James' excellent division of our topic into its members-an omission whose importance may justify my bringing up a phase of the general question to which $I$ think too much importance can hardly be attached. It is, in biological phrase, the ontogenetic question, the examination of development of consciousness in the individual, with a view to the generalization of results and their application to race-development. Professor Cope's emphasis on consciousness rests here, and it is well placed. In the life history of the organism we have the problem of development actually in a measure solved before us. The biologist recognizes this in his emphasis on embryology and also to a degree in his paleontology. But the psychologist has not realized the weapon he has both for biological and for psychological use in the mental development of the child. Moreover the biologist no less than the psychologist must needs resort to this field of investigation if he would finally settle the function of consciousness in evolution. The fossils tell nothing of any such factor as consciousness. Nor does the embryo. So, as difficult as the ontogenetic question is, it is one of the really hopeful fields on both sides. I may be allowed, therefore, to give a brief summary of certain results reached by this method in my own work; especially since it will set out more fully, even in its defects and inadequacies, the general bearing of this problem.

That there is some general principle running through all the conscious adaptations of movement which the individual creature makes is indicated by the very unity of the organism itself. The principle of Habit must be recognized in some general way which will allow the organism to do new things without utterly undoing what it has already acquired. This means that old habits must be substantially preserved in the new functions; that all new functions must be

'See my articles on Heredity and Instinct, Science, March 20 and April 10, ' 96 ; Prof. Cope's reply and my further note may be found in the Amer. Naturalist, April and May, ' 96. 
reached by gradual modifications. And we will all go further and say, I think, that the only way that these modifications can be got at all is through some sort of interaction of the organism with its environment. Now, as soon as we ask how the stimulations of the environment can produce new adaptive movements, we have the answer of Spencer and Bain-an answer directly confirmed, I think, without question, by the study both of the child and of the adult-by the selection of fit movements from excessively produced movements, $i . e$, from movement variations. So granting this, we now have the further question: How do these movement variations come to be produced when and where they are needed $?^{1}$ And with it, the question: How does the organism keep those movements going which are thus selected, and suppress those which are not selected?

Now these two questions are the ones which the biologists fail to answer. And the force of the facts leads to the hypotheses of 'conscious force' of Cope, 'self-development' of Henslow, and 'directive tendency' or 'determinate variation' of the American school-all aspects of the new vitalism which just these questions and the facts which they rest upon are now forcing to the front. Have we anything definite, drawn from the study of the individual on the psychological side, to substitute for these confessedly vague biological phrases? Spencer gave an answer in a general way long ago to the second of these questions, by saying that in consciousness the function of pleasure and pain is just to keep some actions or movements going and to suppress others. The evidence of this seems to me to be coextensive, actually, with the range of conscious experience, however we may be disposed to define the physiological processes which are involved in pleasure and pain. Actions which secure pleasurable conditions to the organism are determined by the pleasure to be repeated, and so to secure the continuance of the pleasurable conditions; and actions which get the organism into pain are by the very fact of pain suppressed.

But as soon as we enquire more closely into the actual working of pleasure and pain reactions, we find an answer suggested to the first question also, $i . e$. , the question as to how the organism comes to make the kind and sort of movements which the environment calls for

${ }^{1}$ This is just the question that Weismann seeks to answer (in respect to the supply of variations in forms which the paleontologists require), with his doctrine of 'Germinal Selection' (Monist, Jan., I896). Why are not such applications of the principle of natural selection to variations in the parts and functions of the single organism just as reasonable and legitimate as is the application of it to variations in separate organisms? 
-the movement-variations when and where they are required. The pleasure or pain produced by a stimulus-and by a movement also, for the utility of movement is always that it secures stimulation of this sort or that-does not lead to diffused, neutral, and characterless movements, as Spencer and Bain suppose : this is disputed no less by the infant's movements than by the actions of unicellular creatures. There are characteristic differences in vital movements wherever we find them. Even if Mr. Spencer's undifferentiated protoplasmic movements had existed, natural selection would very soon have put an end to it. There is a characteristic antithesis between movements always. Healthy, overflowing, favorable, outreaching, expansive, vital effects are associated with pleasure; and the contrary, the withdrawing, depressive, contractive, decreasing, vital effects are associated with pain. This is exactly the state of things which a theory of the selection of movements from overproduced movements requires, $i . e$, that increased vitality, represented by pleasure, should give excess movements, from which new adaptations are selected; and that decreased vitality represented by pain should to the reverse-draw off energy and suppress movement.

If, therefore, we say that here is a type of reaction which all vitality shows, we may give it a general descriptive name, $i$. e., the 'Circular Reaction,' in that its significance for evolution is that it is not a random response in movement to all stimulations alike, but that it distinguishes in its very form and amount between stimulations which are vitally good and those which are vitally bad, tending to retain the good stimulations and to draw away from and so suppress the bad. The term 'circular' is used to emphasize the way such a reaction tends to keep itself going, over and over, by reproducing the conditions of its own stimulation. It represents habit, since it tends to keep up old movements; but it secures new adaptations, since it provides for the overproduction of movement-variations for the operation of selection. This kind of selection, since it requires the direct coöperation of the organism itself, I have called 'Organic Selection.' It might be called ' motor' or even 'psychic' selection, since the part of consciousness, in the form of pleasure and pain, and later on experience generally, intelligence, etc., is so prominent. ${ }^{1}$

'See Chap. VII. on 'The Theory of Development' in my Mental Development in the Child and the Race (2d ed., 1895). I have prepared a new chapter (XVI.) for the German and French editions of this work, incorporating the positions which this view of ontogenetic development leads to in respect to heredity, as suggested in the article referred to in Science. It will appear as an article in the American Naturalist for June, 1896 . It secures determinate variations in phylogeny, without the inheritance of acquired characters. 
This is a psychological attempt to discover the method of the individual's adaptations; it has detailed applications in the field of higher mental process, where imitation, volition, etc., give direct exemplifications of the circular type of reaction. But if the truth of it be allowed by the biologist for the individual's development, it follows from the doctrine of recapitulation that this type function shall run through all life. This would mean that something analogous to consciousness (as pleasure and pain, etc.,) is coextensive with life, and that the vital process itself shows a fundamental difference in movements-analogous to the difference between pleasure-incited and painincited movements. The biologist may say that this is too specialthis difference of reaction-to be fundamental; so it may be. But then so is life special, very special!

Whatever we may say to such particular conclusions, they illustrate one of the topics which should be discussed by anyone, biologist or psychologist, who wants to find all the factors of evolution. There are some factors revealed in ontogenesis which do not appear in the current theories of phylogenetic evolution. Indeed, so far beside the mark are the biologists who are discussing heredity to-day that they generally omit-except when they hit at each other-the two factors which the psychologist has to recognize; Social Heredity, for the transmission of socially-acquired characters, and Organic Selection, for the accommodations of the individual organism, and through them of 'determinate variations' in phylogeny.

Indeed, I do not see how either theory of heredity can get along without this appeal to ontogenesis. For if we agree in denying the inheritance of acquired characters, thus throwing the emphasis on variations, still it is only by the interpretation of ontogenic processes and characters that any general theory of variations can be reached. Either experience causes the variations, as one theory of heredity holds ; or it exemplifies them, as the other theory holds; in either case, it is the only sphere of fact to which appeal can be made if we would understand them. So why do biologists speculate so long and so loud on the question of the mode of transmission, when the question of the mode of acquisition is so generally neglected by them?

The only additional point which I may claim a little time to speak of is that to which Professor James referred in describing the current doctrines of the relation of mind and body. He described the view that consciousness does not in any way interfere with the activities of the brain, as the 'automaton theory,' and spoke as if in his mind a real automatism-a view which considered the brain processes as the 
sufficient statement of the causes of all voluntary movement-was the outcome of any denial of causal energy in consciousness. In other words that there is no alternative to what is called the epi-phenomenon theory of consciousness except a theory holding that the law of conservation of physical energy is violated in voluntary movement.

Now this reduction of the possible views to two is, in my view, unnecessary and, indeed, impossible. In speaking of the antecedents of a voluntary movement we have to consider the entire group of phenomenal events which are always there when voluntary movement takes place; and among the phenomena really there the conscious state called volition is really there. To say that the same movement could take place without this state of consciousness is to say that a lesser group of phenomenal antecedents occurs in some cases and a larger group in other cases of the same event. Why not go to the other extreme, and say that the brain is not necessary to voluntary movement, since volition could bring about the movement without using the nervous processes to do it with? In his posthumous book on Matter and Monism, the late Mr. Romanes brings out this inadequacy of the automaton view, using the figure of an electro-magnet, which attracts iron filings only when it is magnetized by the current of electricity. Whatever the electricity be, the magnet is a magnet only when it attracts iron filings; to say that it might do as much without the electricity would be to deny that it is a magnet; and the proof is found in the fact simply that it does not attract iron-filings when the current is not there. So the brain is not a brain when consciousness is not there; it could not produce voluntary movement, simply because, as a matter of fact, it does not. So consciousness does not, on the other hand, produce movement without a brain. The whole difficulty seems to lie, I think, in an illegitimate use of the word 'causation.' Professor Ladd seems to me to be correct in holding that such a conception as physical causation can not be applied beyond the sphere of things in which it has become the explaining principle, $i . e$. , in the objective, external world of things. The moment we ask questions concerning a group of phenomena which include more than these things, that moment we are liable to some new statement of the law of change in the group as a whole. Such a statement is the third alternative in this case; and it is the problem of the metaphysics of experience to find the category, or the most general principles of experience as a whole, both objective and subjective. This $I$ do not care to discuss, but $I$ am far from thinking that the automaton or epi-phenomenon man can argue his case with much force in this higher court of appeal. 
The other extreme is represented by those writers who think that the revision of the law of causation can be made in the sphere of objective phenomenal action represented by the brain; and so claim that there is a violation of the principle of conservation of energy in a voluntary movement, an actual efficiency of some kind in consciousness itself for producing physical effects. This is as illegitimate as the other view-is it not? It seems to deny the results of all objective empirical science and so to sweep away the statements of law (on one side) on which the higher interpretation of the group of phenomena as a whole must be based. And it does it in favor of an equally empirical statement of law on the other side. I do not see how any result for the more complex system of events can be reached if we deny the only principles which we have in the partial groups. To do so is to attempt to interpret the objective in terms of the subjective factor in the entire group; and we reach by so doing a result which is just as partial as that which the epi-phenomenon man reaches in his mechanical explanation. Lotze made the same mistake long ago, but his hesitations on the subject showed that he appreciated the difficulty. I agree with these writers in the claim that the mechanical view of causation can not be used as an adequate explaining principle of the whole personality of man; but for reasons of much the same kind it seems equally true that as long as we are talking of events of the external kind, $i$. e., of brain processes, we can not deny what we know of these events as such.

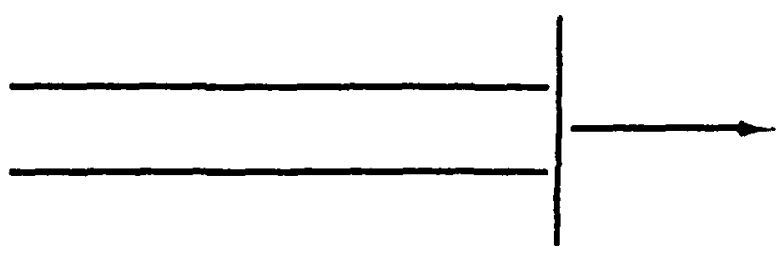

The general state of the problem may be shown by the accompanying diagram, which will at any rate serve the modest purpose of indicating the alternatives. The line above, of the two parallels, may represent the statements on the psychological side which, on the theory of parallelism, mental science has a right to make; the lower of the parallels, the corresponding series of statements made by physics and natural science, includes the chemistry and physiology of the brain. Where they stop an upright line may be drawn to indicate the setting of the problem of interpretation in which both the other series of 
statements claim to be true; and the further line to the right then gives the phenomena and statements of them which we have to deal with when we come to consider man as a whole. Now my point is that we can neither deny either of the parallel lines in dealing with the phenomena of the single line to the right, nor can we take either of them as a sufficient statement of the farther problem which the line to the right proposes. To take the line representing the mechanical principles of nature and extend it alone beyond the upright is to throw out of nature the whole series of phenomena which belong in the upper parallel line and are not capable of statement in mechanical terms. And to extend the upper line alone beyond the upright is to allow that mechanical principles break down in their own sphere.

As to the interpretation of the single line to the right, it may always remain the problem that it now is. The best we can do is to get points of view regarding it; and the main progress of philosophy seems to me to be in getting an adequate sense of the conditions of the problem itself. From the more humble side of psychology, I think the growth of consciousness itself may teach us how the problem comes to be set in the form of seemingly irreconcilable antinomies. The person grows both in body and mind, and this growth has to have two sides, the side facing toward the direction from which, the 'retrospective reference,' and the side facing the direction toward which, the 'prospective reference' of growth and the consciousness of growth. The positive sciences have by their very nature to face backwards, to look retrospectively, to be 'descriptive,' as the term is used by Professor Royce-these give the lower of our parallel lines. The moral sciences, so-called, on the other hand, deal with judgments, appreciations, organizations, expectations, and so represent the other, the 'prospective' mental attitude and its corresponding aspects of reality. This gives character largely to the upper one of our parallel lines. But to get a construction of the further line, the one to the right, is to ask for both these points of view at once-to stand at both ends of the line-at a point where description takes the place of prophecy and where reality has nothing further to add to thought. I believe for myself that the best evidence looking to the attainment of this double point of view is found just in the fact that we are able to compass both of these functions in a measure at once; and that in our own self-consciousness we have an inkling of what that ultimate point of view is like.' I do not mean to bring up points in philosophy;

II may refer to the extended use made of this general antithesis in $\mathrm{my}$ paper in this Review for November, 1895 , and to the philosophical considerations based on it by Mr. W. M. Urban in the number of January, 1896. 
but it is to me the very essence of such a contention in philosophy that it is a comprehension of both aspects of phenomenal reality and not the violation or denial of either of them.

J. Mark Baldwin.

Princeron.

\section{PAIN NERVES.}

That specific nerves of pain have at last been established with a certainty fully equal to that for any of the other dermal nerves is an event, for psychology, of the first magnitude. Considering the rofle that traditional pain-pleasure dogmas have played in fundamental conceptions of mind, in ethical theories, and in philosophic deductions, it is perhaps not too much to say that this event is one of the most important determinations happening within the epoch of Modern Psychology.

I refer to the demonstration of pain-nerves through clinical evidence by Dr. Henry Head, of University College Hospital. ${ }^{2}$ To many the revolution in conceptions which this work must necessitate will cause bewilderment, and perhaps also a lingering skepticism. For it was but a few months ago that Dr. Strong presented to the public his reports ${ }^{2}$ - which from their grave judicial tone had quite the appearance of being official-assuring us that according to his summary of the evidence the existence of special pain-nerves was 'more than doubtful;' which, of course, from this accurate writer could alone mean that they were no longer possible. Yet at the very time of Dr. Strong's writing (1895) the magnificent report of Dr. Head, which must set this dispute at rest forever, had been nearly two years in print in the official journal of Neurology for the English Language, and had been twice read in public the year previous ( 1892 ).

The proof which Dr. Head's work offers for separate pain-nerves rests on clinical demonstration that the skin of the body is divided into definite zones of nerve-supply for pain, which zones do not correspond to the zones of nerve-distribution for touch. These zones for pain are coextensive with those for heat, cold and trophic nerves, and all of these four kinds of nerves (pain, heat, cold and trophic) supplying any given zone have common origin in a single corresponding segment of the cord. In other words, each segment of the cord has its own zone of distribution for these four kinds of nerves. These zones are sharply

1 Disturbances of Sensation with especial reference to the Pain of Visceral Disease. By Henry Head, M. A., M. D. Brain, 1893, p. I, and 1894, p. 339. 2 Psy, Rev., March, 1895, p. 44, July, 1895, and January, 1896. 